\title{
Türkiye'de Ekonomik Göstergeler ve Para Arzının Bireysel Kredi Kartı Kullanımına Etkileri
}

\author{
The Effects of Economic Indicators and Money Supply on Individual Credit \\ Card Usage in Turkey
}

Öz

Bireysel kredi_kartı kullanımının yaygınlaşmasıyla hane halkının kayıt altına alınan tüketim, borçlanma ve tasarruf davranışlarının incelenmesi mümkün olmuş ve bireyin iktisadi davranışlarının ekonomiye yansımaları birçok çalışmaya konu edilmiştir. Bu çalışmada bireysel kredi kartı kullanımı ile para arzı ve ekonomik göstergeler arasındaki ilişkisi Türkiye düzeyinde araştırılmıştır. Bireysel kredi kartı kullanımının reel hacmi ile reel para arzi, sanayi üretim endeksi, tüketici fiyat endeksi-D, bankalararası gecelik faiz oranı ve USD döviz kuruna ait 2005M12019M8 dönemini kapsayan aylık veri setiyle çalışılmıştır. Granger nedensellik analizi sonuçlarnna göre, sanayi üretim endeksi, tüketici fiyat endeksi, faiz oranı, para arzı ve döviz kurundan kredi kartı kullanımına doğru tek yönlü nedensellik ilişkisi bulunmuştur. Özetle, analiz sonuçları bireysel kredi kartı kullanımının ekonomik göstergelerden ve para arzindan etkilendiğini göstermektedir.

\footnotetext{
Abstract

With the spread of individual credit card usage, it is possible to examine the recorded consumption, borrowing and saving behaviors of households and the reflections of the individual's economic behaviors to the economy. In this study, the relationship between individual credit card usage with money supply and economic indicators were investigated in Turkey. For this purpose, the data set of the real volume of individual credit card transaction and the real money supply, industrial production index, consumer price index-D and interbank overnight interest rate and USD exchange rate were used, for the monthly period over 2005M12019M8. According to the Granger causality analysis results, we found that the unidirectional causality relationship from industrial production index, consumer price index, interest rate, money supply and exchange rate to credit card usage. In summary, analysis results indicate that individual credit card usage is affected by economic indicators and money supply.

\section{Giriş}

Kredi ve banka kartları başta olmak üzere elektronik ödeme araçlarının yaygın kullanımı günden güne artmaktadır. Dünyadaki orta üstü gelir grubundaki nüfusun 15 yaş üstü kısmının \%38,1'i ve Avrupa ile Orta Asya' daki 15 yaş üstü nüfusun \%38,5'u banka ve kredi kartı kullanırken, Türkiye'de bu oran \% 47,6 seviyesindedir (Worldbank, Global Findex Database 2018:150). Türkiye' de kredi kartı kullanımı 1990'lı yıllarda başlamış; kredi kartı kullanım hacmi 2018 sonunda 66,3 milyon seviyesine ulaşmıştır. 2010-2018 döneminde alışverişlerde kredi kartı kullanımı yaygınlaşmış ve özellikle internetten yapılan işlem hacmi büyük bir ivme kazanmıştır. Günümüzde internetten yapılan harcamalar (\%19) kredi kartı harcamaları içinde en büyük paya sahiptir. İkinci sırada ise market ve alışveriş merkezlerinde gerçekleştirilen kredi kartı harcamaları (\%17) gelmektedir (TCMB EVDS, 2019a).
} 
Tablo 1. Yerli Kredi Kartlarının Yurtiçi ve Yurtdışı Kullanımı (2010-2018)

\begin{tabular}{|l|r|r|r|r|r|}
\hline & $\mathbf{2 0 1 0}$ & $\mathbf{2 0 1 2}$ & $\mathbf{2 0 1 4}$ & $\mathbf{2 0 1 6}$ & $\mathbf{2 0 1 8}$ \\
\hline Kredi Kartı sayısı (milyon adet) & 47 & 54 & 57 & 59 & 66 \\
\hline İşlem Sayısı (milyon adet) & 2046 & 2518 & 2822 & 3229 & 3945 \\
\hline İşlem Hacmi (milyon TL) & 234492 & 361329 & 474218 & 601855 & 794305 \\
\hline $\begin{array}{l}\text { İnternetten Yapılan İşlem Sayısı } \\
\text { (milyon adet) }\end{array}$ & 80 & 146 & 218 & 307 & 513 \\
\hline $\begin{array}{l}\text { İnternetten Yapılan İşlem Hacmi } \\
\text { (milyon TL) }\end{array}$ & 11787 & 24787 & 40849 & 68883 & 132627 \\
\hline
\end{tabular}

Kaynak: BKM (2019a), (Erişim Tarihi: 20.11.2019).

Bireysel kredi kartı kullanımı toplam tüketici kredileri içerisinde \% 21 oranında bir paya sahiptir (BDDK, 2019a). Ödemelerde kart kullanımının sağladığı bazı avantajlar bulunmaktadır. Bu avantajların ilki tüketicinin ödemelerini nakit para kullanmadan, ön ödemeli kartlarla yaparak hesabından nakit para çıkışını erteleyebilmesi ve nakit parası olmasa dahi alışveriş yapabilme fırsatını yakalayabilmesidir. Diğer avantajlar arasında kredi kartının küçük tutarlı gündelik alışverişlerde kullanılabilmesi, kredi kartıyla ödeme yapmanın nakit taşımaktan daha güvenli ve kolay olması, kart ödemelerinde sağlanan kolaylık ve esneklikler bulunmaktadır. Devlet açısından kredi kartı harcamalarının kayıt altına alınabilmesi önemli bir avantaj sağlamaktadır. Kayıt altına alınan harcamalar dolayısıyla vergi gelirleri artmaktadır (BKM, 2019b).

Dünyada olduğu gibi Türkiye'de bireysel kredi kartı kullanımındaki büyük artışın negatif tarafları da bulunmaktadır. Negatif tarafların başında tüketicinin kredi kartı borç yükünü taşıyamayacağı boyutta arttırması gelmektedir.

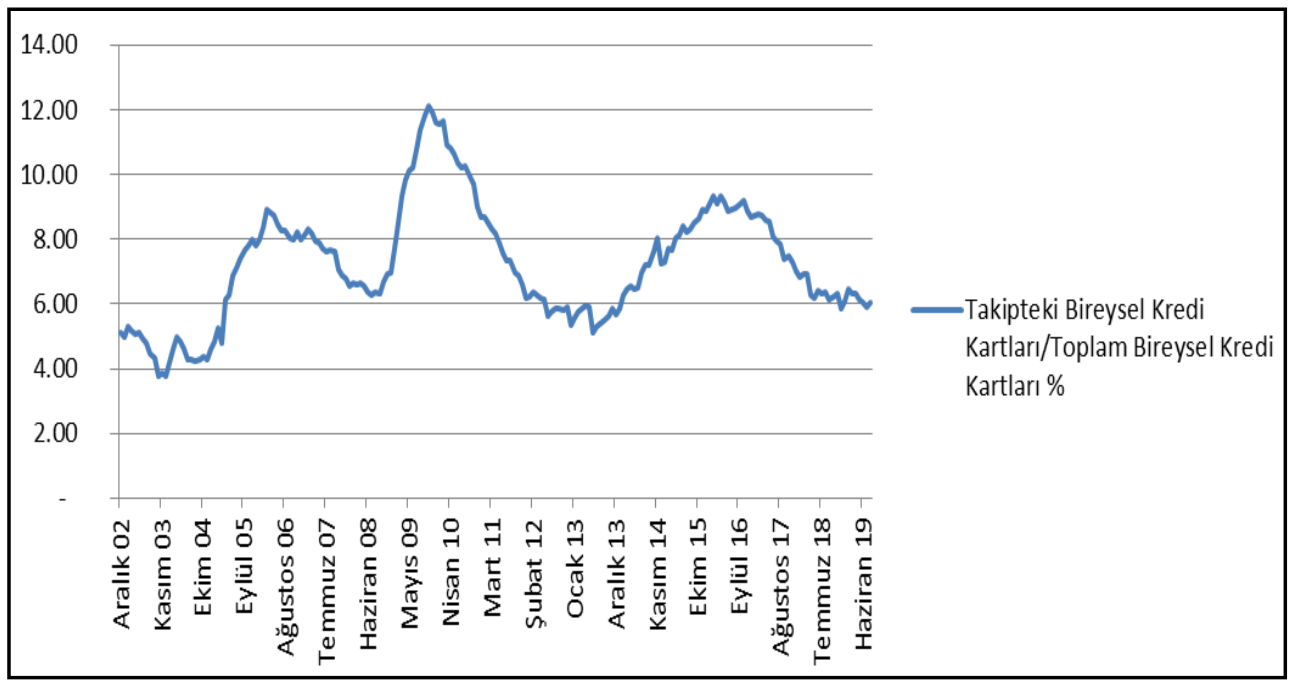

Grafik 1. Takipteki Bireysel Kredi Kartları/Toplam Bireysel Kredi Kartları \% (2002 Aralık - 2019 Haziran Dönemi)

Kaynak: BDDK (2019c).

Türkiye' de toplam tüketici kredileri içinde takibe dönüşüm oranı en yüksek kredi türü bireysel kredi kartlarıdır (BDDK, 2019a). 2002-2019 döneminde dalgalı bir seyir izleyen bireysel kredi kartı takibe dönüşüm oranında en büyük artış 2008 Küresel Krizi'nin ertesinde yaşanmıştır (Grafik 1). Daha ucuz borçlanma alternatifi bulamayan özellikle düşük gelir grubundaki tüketiciler, yüksek maliyetine rağmen kredi kartı borçluluğunu sürdürebilir (Stavins, 2018:1). Temerrüde düşen kredi kartlarında artış olduğu dönemlerde enflasyon daha fazla yükselmekte ve kredi kartlarından daha az verimlilik elde edilmektedir (Geanakoplos ve Dubey, 2010:325). Kredi kartı işlem hacminin düştüğü bu dönemde para otoritelerinin para arzını azaltması halinde ekonomideki durgunluk artmaktadır (Geanakoplos ve Dubey, 2010:338). Özellikle kriz dönemlerinde kredilerin kisitlı olması, bazı tüketicilerin kredi kartlarında fazla borçlanmalarına ve borçlarının tamamını ödeyememelerine, temerrüde düşmelerine neden oluyorsa, politika yapıcılar temerrüt ve kanuni 
takibe düşme olasılığını azaltmak için düşük gelirli ve kredi kısıtı olan tüketicilere daha az maliyetli kredi seçenekleri üretebilirler (Akın vd., 2019: 23).

Türkiye'de kredi kartı ödemelerinin gecikmesi ve takibe düşen kredi kartı sayısındaki artış ihtimalinin endişe yarattığı dönemlerde düzenleyici otoritelerin bu konuda önlem aldıkları gözlenmektedir. Nitekim BDDK, hızlı büyümenin yaratabileceği olumsuzlukları engellemek için makro ihtiyati tedbirleri uygulamaya koymuş, 2010 yılından itibaren kredi kartlarında asgari ödeme seviyesi yükseltilmiştir. Tüketicinin kart limitleri gelirleriyle sabitlenmiş, limit artışları ve taksitli alımlara, nakit avans kullanımına yönelik kısıtlayıcı düzenlemeler getirilmiştir. Son düzenlemelerden biri de BDDK'nın 11.01.2019 tarihli toplantısında aldığ 8198 sayılı kararda mal ve hizmet alımına ilişkin borcun en fazla 12 aya kadar taksitlendirilebileceği belirtilmiş, bazı ürünler için bu süre daha da aşağıya çekilmiş, hatta bazılarında taksitlendirme tamamen kaldırılmıştır (BDDK, 2019b).

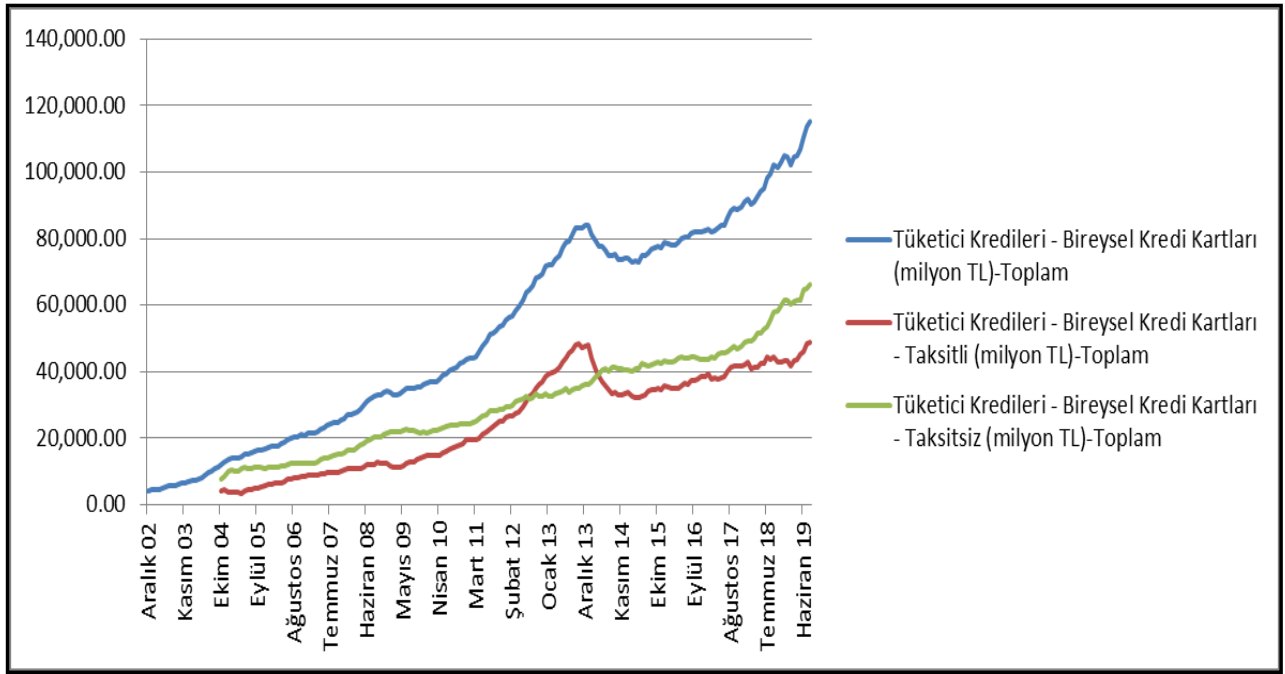

Grafik 2. Bireysel Kredi Kartları (2002 Aralık - 2019 Haziran Dönemi) Kaynak: BDDK, (2019c).

Kredi kartlarındaki taksitsiz kullanımlar, belirli dönemler dışında, taksitli kullanımlardan daha yüksek bir hacime sahiptir. Haziran 2019' da 46 milyar TL taksitli ve 65 milyar TL taksitsiz olmak üzere bireysel kredi kartı toplam tutarı 111 milyar TL seviyesindedir (Grafik 2). Bireysel kredi kartlarında vade ve taksit kısıtlamaları, Türkiye'de hanehalkına ait kredi riski görünümünü iyileştirmiştir. Böylece hanehalkı borçluluğunda daha tedbirli bir düzene geçilmiştir. Türkiye'de hanehalklarının toplam kredi kullanımının GSYİH'ya oranı, gelişmiş ve gelişmekte olan ekonomilerin altında kalmaktadır. 2019'un birinci çeyreğinde \% 14,30 olduğu bu oranın aynı dönemde gelişmiş ülkelerde \%72'ye, gelişmekte olan ülkelerde ise \% 41,60'a ulaştı̆̆ 1 gözlemlenmektedir (TCMB EVDS, 2019b). Türkiye ekonomisinde tüketimin milli gelir içinde büyük bir paya sahip olması ve yapısal cari açı̆̆ın varlığı nedeniyle hanehalkı borçlanması ve bireysel borçlanma dinamikleri, finansal istikrarın tesisi ve sürdürülebilirliği için takip edilmelidir (Eroğlu, 2018:1).

Bu çalışmada Türkiye'de bireysel kredi kartı kullanımını etkileyen ekonomik ve finansal faktörler araştırılmaktadır. Bu amaçla bireysel kredi kartlarının kullanım hacmi ile milli gelir, fiyatlar genel düzeyi, politika faiz oranı, döviz kuru ve merkez bankası dar para arzı arasındaki ilişki 2005M1-2019M8 aralığındaki aylık veri setiyle ampirik analiz yapılarak incelenmiştir.

Çalışmanın bundan sonraki bölümünde kredi kartı kullanımını etkileyen faktörler incelenmiş, ikinci bölümde literatür taraması yapılmıştır. Üçüncü bölümde ise ekonometrik metodoloji ve dördüncü bölümde araştırma bulguları raporlanmıştır. Son bölümde analiz sonuçları tartışılmış ve genel değerlendirme yapılmıştır. 


\section{Kredi Kartı Kullanımını Etkileyen Faktörler}

Kredi kartı kullanımını etkileyen faktörlerden bazıları bireysel niteliktedir. Bireyler tasarruf, borçlanma ve harcama konusunda farklı finansal davranışlar gösterebilir. Örneğin düzenli bir geliri olmayan birey, tüketimini kredi kartıyla yapmayı tercih etmeyebilir. Başka bir birey kredi kartı borç bakiyesinin tamamını ödemeyip, sadece asgari ödeme tutarını ödemeyi tercih edebilir. Bireyin kredi kartı kullanımını finansal bilgi düzeyi, davranış ve tutumu, krediye ulaşabilir olması, gelir düzeyi, yaşam döngüsü değişkenleri, yaş ve cinsiyet gibi demografik faktörler etkileyebilir (Akın vd., 2019:.3,7-9,11). Özetle kredi kartları bireylerin borçlanma, tüketim ve tasarruf kararlarının temel yönlerini birleştirmektedir. Birincisi tüketiciler gelirleri düşse bile tüketim yapabilmeyi (likidite ve tedbir amacıyla), ikincisi kısa ve uzun vadeli borçlarını döndürebilmeyi (yaşam döngüsü), üçüncüsü ödemelerin bir kısmında nakit çıkışını erteleyebilmeyi amaçlarlar (Fulford ve Schuh, 2017:2). Akın vd. (2019) tarafından Türkiye düzeyinde 2009 yılında yapılmış anket çalışması üzerinden bireyin kredi kartı borçluluk düzeyi araştırılmıştır. Analiz bulgularına göre, bireyin geliri ve kullanabileceği kredilerin kısıtlı olmasının borçluluk davranışlarında etkili faktörler olduğu sonucuna ulaşılmıştır. Ayrıca gelir döngüsünün ideal olmayışının ve daha ucuz fonlara ulaşılamamasının borçluluğun artışında finansal okuryazarlığa sahip olmamaktan daha etkili olduğu tespit edilmiştir.

Toplam kredi kartı kullanımını etkileyen makroekonomik düzeyde faktörler bulunmaktadır. Bu faktörler (a) fiyatlar genel düzeyi (b) kredi kartı borcu zamanında ödenmediği takdirde kredi kartı borç tutarına uygulanan faiz oranı (c) döviz kuru (d) üretim düzeyi şeklinde siralanabilir (Y1lmazkuday, 2010:2-3).

Kredi kartının yaygın kullanımı ticaretin verimliliğine katkı sağlamaktadır. Ancak aynı zamanda paranın dolaşım hızını arttırır ve parasal otoritelerce piyasaya müdahale edilmemesi halinde enflasyona neden olabilir. Eğer para otoritesi para arzını azaltarak eski fiyat seviyesini yeniden kazanmaya çalışırsa verimlilik kazanımlarından vazgeçmek zorunda kalabilir. Teorik olarak, paranın dolaşım hızı para talebiyle ters orantılıdır ve kredi kartı kullanımı nedeniyle para talebinin daha düşük olması paranın dolaşım hızını arttırmaktadır. Paranın dolaşım hızındaki artış seviyesi enflasyonu artırır ve bu durum merkez bankasının enflasyon hedefinden sapmasına neden olabilir (Geanakoplos ve Dubey, 2010:325).

Ayrıca düşük para talebi merkez bankasının bilançosunu daraltarak merkez bankasının rezervlerine olan talebi azaltabilir. Dolayısıyla düşük para talebi, merkez bankasının kısa vadeli faiz oranını açık piyasa işlemleriyle etkileme yeteneğini azaltabilir (Friedman, 1999:321 ; Freedman, 2000:21).

Literatürde kredi kartlarının yaygınlaşmasının nakit kullanımını tamamen ortadan kaldıracağını savunan görüşler de bulunmaktadır. Enflasyonun ve faiz oranlarının düşük olduğu dönemlerde bu görüss savunulabilir. Ancak enflasyonun ve faiz oranlarının yüksek olduğu durumlarda, tüketici açısından kredi kartıyla alış veriş yaparak nakit transferini ertelemek cazip görünse de satıcı için kredi kartıyla satış pek de cazip olmayabilir. Böylece alışverişte satışa konu ürünün nakit fiyatının kredi kartıyla satış fiyatından düşük olduğu durumlarda nakit ve kredi kartı, birbirine alternatif ödeme seçenekleri olarak, kabul edilmektedir (Geanakoplos ve Dubey, 2010:332).

\section{Literatür Taraması}

Literatürde kredi kartı kullanımı çeşitli açılardan, farklı yöntemler kullanılarak çalışılmıştır. Aşağıda (a) kredi kartı kullanımındaki artışın nakit kullanımı ile para politikasına etkisinin araştırıldığı çalışmalardan bazıları ile (b) ekonomik göstergeler, para politikası, parasal büyüklükler ile kredi kartı kullanımı arasındaki ilişkilerin incelendiği çalışmalardan bazıları raporlanmıştır.

Prabheesh ve Rahman (2019), Endonezya' da kredi kartları ile para politikası ilişkisini, 2006-2018 dönemine ilişkin milli gelir, enflasyon, borç verme faiz oranı, politika faiz oranı, döviz kuru, petrol fiyatları verileri ile yapısal VAR modelinden yararlanarak analiz etmiştir. Sonuçlara göre kredi kartı kullanımındaki artışın temelde Endonezya'nın ekonomik büyümesinden kaynaklanabileceği bulunmuştur. Borç verme kanalıyla para politikası aktarımının zayıf olduğu, parasal aktarım sürecinde döviz kurları ile küresel petrol fiyatlarının daha yaygın bir rol oynadığı tespit edilmiştir. 
Sönmezler vd. (2019), Türkiye' de kredi kartı alışveriş tutarı ile geçinme endeksi ve tüketici güven endeksi arasındaki ilişkiyi 2012M2 ile 2018M2 döneminde ARDL sınır testi yaklaşımıyla analiz etmiştir. Değişkenlerin eşbütünleşik olduğu tespit edilmiştir. Ayrıca tüketici güven endeksinin kredi kartı harcamaları üzerinde etkisi, incelenen dönem verileriyle, istatistiksel olarak anlamsız bulunmuştur. Geçinme endeksinin uzun dönemde kredi kartı harcamalarını pozitif yönde etkilediği tespit edilmiştir.

Mazibaş ve Tuna (2017), Ocak 2004 ile Aralık 2013 dönemine ilişkin aylık veri setiyle Türkiye' de tüketici kredileri ve bireysel kredi kartları ile GSYİH, 1 yıl vadeli mevduat faiz oranı \%, BIST 100 endeksi, M2 para arzı, tüketim malları ithalatı, tüketici güven endeksi, tüketici fiyat endeksi arasındaki ilişkiyi ARDL modeli ile Toda-Yamamoto nedensellik testiyle analiz etmişlerdir. ARDL testi sonuçlarına göre, tüketici kredileri ve bireysel kredi kartları ile BIST ve tüketim malları ithalatı arasında anlamlı ve uzun vadeli bir ilişki bulunmuştur. Ayrıca tüketici kredileri ve bireysel kredi kartları ile GSYİH ve 1 yıllık mevduat faiz oranı arasında güçlü bir uzun dönem ilişkisi bulunmuştur. Nedensellik analizi sonuçlarına göre kısa dönemde BIST 100 endeksi, GSYİH ve 1 yıllık mevduat faiz oranından tüketici kredileri ve bireysel kredi kartlarına doğru tek yönlü nedensellik ilişkisi tespit edilmiştir.

Balaylar vd. (2017), Ekim 2004 ile Haziran 2017 aralığında, Türkiye' de döviz kurlarıyla kredi türleri arasındaki ilişkiyi araştırmıştır. Analiz sonuçlarına göre kredi kartı kullanım miktarıyla döviz kurları arasında uzun dönemde ilişki olduğu tespit edilmiştir. Granger nedensellik analizi sonuçlarına göre kısa dönemde kredi kartı kullanım tutarlarının farklı döviz cinsleri arasında nedensellik ilişkisi tespit edilmiştir.

Yüksel vd. (2016), Türkiye' de makroekonomik faktörlerin kredi kartı kullanımına etkisini MARS yöntemini kullanarak Ocak 2005 ve Şubat 2016 dönemine ilişkin verilerle araştırmıştır. Analiz sonucunda kredi kartı kullanımıyla işsizlik oranı arasında negatif yönlü ilişki tespit etmişlerdir. Ayrıca faiz oranları yükseldiğinde kredi kartı kullanımının arttığını raporlamışlardır.

Kabarlarlı (2015), yurtiçinde kullanılan kredi kartları ile tüketici fiyat endeksi aylık değişimi \%, bankalarca açılan kredilere uygulanan ağırlıklı ortalama faiz oranı, sanayi üretim endeksi arasındaki ilişkiyi VAR yöntemini kullanarak 2005-2014 dönemine ilişkin aylık veri setiyle incelemiştir. Etki tepki analizi sonuçlarına göre, kredi kartı kullanımının para arzındaki değişime tepkisi zayıftır. Kredi kartı kullanım tutarının varyans ayrıştırmasında kredi kartı kullanımının kendisinden sonra sırasıyla tüketici fiyat endeksi, faiz oranı, M1 para arzı ve sanayi üretim endeksinin geldiği ve değişkenlerin kredi kartı kullanımı üzerinde küçük açılama paylarına sahip oldukları belirtilmiştir.

Karpuz (2012), 2001-2011 dönemini ikiye bölerek VAR modelinde etki-tepki fonksiyonunu incelemiştir. Bireysel ve ticari kredilerin hacimlerindeki aylık değişim, M1/GSYİH, bankalararası gecelik faiz oranı, GSYİH'daki aylık değişim, TÜFE'deki aylık değişim, VIX endeksindeki aylık değişim mevsimsellikten arındırılarak modele dahil edilmiştir. Kredi kartlarının ekonomide yaygın kullanımı durumunda MB para politikasına verilen tepkinin gecikebileceği tespit edilmiştir. Ayrıca genişletilmiş para politikası sonucu faiz oranı düştügüünde, kullanılan kredinin arttığı ve artan kredi hacmi sonucu GSYİH'nın kısa süreli artışının beklendiğini raporlamıştır.

Yılmazkuday ve Yazgan (2011), Türkiye' de kredi ve banka kartlarının dolaşımda bulunan para hacmi üzerindeki etkisini GMM tahmin yöntemiyle 2002M1-2006M10 döneminde aylık veriler kullanarak incelemişlerdir. Teoride beklendiği gibi, kredi kartı ve banka kartı kullanımındaki artışın para talebini azalttığı tespit edilmiştir. Banka kartlarının kredi kart kullanımına kıyasla para talebi üzerinde daha büyük etkiye sahip olduğunu bulgulamışlardır. Kredi kartlarının çoğunlukla satın alımlarda ve banka kartlarının çoğunlukla nakit çekme işlemlerinde kullanıldığı tespit edilmiştir.

Yılmazkuday (2010), Türkiye'de kredi kartları kanalıyla para politikası aktarım kanalının işleyişini 2002-2009 aralığında sanayi üretim endeksi, reel kredi kartı kullanım hacmi, kısa dönem faiz oranı (bankalararası gecelik faiz oranı), enflasyon oranı, EURO/TL döviz kuruna ilişkin aylık verileri kullanarak incelemiştir. Tüm değişkenlerin yıllık değişim oranları alınmış ve HodrickPrescott filtresiyle mevsimsellikten arındırılmıştır. 2002M1-2005M12 aralığı ile 2006M1-2009M12 aralığındaki aylık verileri ayrı ayrı VAR modelini kullanarak analiz edilmiştir. Sonuçlar kredi kartı kullanımının enflasyon oranı üzerinde zamanla artan bir etkiye sahip olduğunu göstermektedir. 
Kısa vadeli faiz oranları enflasyon, kur şokları ve gecikmeli faiz oranlarından olumlu yönde etkilenmektedir. Faiz oranlarının kredi kartı ve milli gelir üzerinde önemli bir etkisi yoktur. Enflasyon oranı döviz kuru şoklarından ve gecikmeli enflasyon oranlarından etkilenmiştir. Milli gelir çoğunlukla döviz kurlarındaki şoklardan etkilenmiştir. Kredi kartı kullanımı, en çok milli gelir şokları ve iki döneme kadar gecikmeli kredi kartı kullanımından olumlu etkilenmiştir. Faiz oranlarındaki şoklardan en çok döviz kurları etkilenmiştir.

Uzgören vd. (2007), Türkiye'de kredi kartı harcamalarını etkileyen faktörleri incelemek amacıyla 1994-2004 zaman aralığında pos sayısı, kişi başına düşen GSMH, kredi kartı sayısı, enflasyon oranı aylık verileri ile 2000-2001 krizinin yapay değişken olarak modele dahil edildiği, çoklu regresyon analizi yapmıştır. Araştırmacılar kredi kartı harcamalarının POS sayısı, kişi başına düşen GSMH, kredi kartı sayısı, enflasyon oranı ile doğru yönlü, finansal krizlerin kredi kartı harcamaları üzerine ters yönlü ilişkili olduğunu tespit etmişlerdir.

\section{Ekonometrik Metodoloji}

$\mathrm{Bu}$ çalışmada incelenen zaman serileri arasındaki ilişkileri analiz etmek amacıyla ADF ile Lumsdaine-Papell (1997) birim kök testleri ve Granger nedensellik yöntemi kullanılmıştır.

\subsection{Lumsdaine-Papell (1997) Birim Kök Testi}

Zaman serilerinde yapısal kırılmanın varlığı durumunda, kurulacak regresyon modellerinde bu yapısal kırılmaların dikkate alınması büyük önem arz etmektedir. Yapısal kırılma tarihlerini dikkate almayan regresyon modellerinden hesaplanacak öngörü ve tahmin sonuçları sistematik sapmalı olmaktadır (Sevüktekin ve Nargeleçekenler, 2010:389). Bu nedenle, literatürde yapısal kırılmaları dikkate alan birim kök testleri geliştirilmeye başlanmıştır. İlk olarak, Perron 1989 yılında zaman serilerinde tek kırılmayı dikkate alan Perron birim kök testini geliştirmiştir. Ancak, bu testte kırılma tarihinin önceden bilindiğinin kabul edilmesi büyük problem teşkil edilmektedir. Zivot ve Andrews (1992) ise geliştirdikleri Zivot-Andrews (ZA) birim kök testinde bu problemin üstesinden gelmektedir. Bu teste göre, zaman serilerinde gerçekleşen tek yapısal kırılma noktası geliştirilen model tarafından içsel olarak belirlenebilmektedir.

Serilerde kırılma nokta sayısının birden büyük olması durumunda Perron (1989) ve ZA birim kök testlerinin tahmin bulguları yanıltıcı olabilmektedir. Bu sebeple, Lumsdaine ve Papell (1997) iki yapısal kırılmayı dikkate alan Lumsdaine-Papell (LP) birim kök testini geliştirmişlerdir.

LP testi, ZA birim kök testinin iki yapısal kırılma için geliştirilmiş bir versiyonudur. LP birim kök test istatistiği aşağıda yer alan modellerin tahminine dayanmaktadır:

$$
\begin{aligned}
& \Delta x_{t}=\mu+\beta t+\varphi_{1} D U 1_{t}+\varphi_{2} D U 2_{t}+\alpha x_{t-1}+\sum_{j=1}^{k} b_{j} \Delta x_{t-j}+\varepsilon_{t} \\
& \Delta x_{t}=\mu+\beta t+\varphi_{1} D U 1_{t}+\varphi_{2} D U 2_{t}+\omega_{1} D T 1_{t}+\omega_{2} D T 2_{t}+\alpha x_{t-1}+\sum_{j=1}^{k} b_{j} \Delta x_{t-j}+\varepsilon_{t}
\end{aligned}
$$

Sirasıyla Denklem (3.1) ve Denklem (3.2)'deki modeller sırasıyla, Model AA ve Model CC olarak adlandırılır. Model AA, trend fonksiyonun düzeyinde iki yapısal kırılmaya izin vermektedir. Model $\mathrm{CC}$ ise trend fonksiyonun hem düzey hem de eğiminde iki yapısal kırılmaya izin vermektedir. $t=1,2, \ldots, T$ için, $D U 1_{t}$ ve $D U 2_{t}$ sırasıyla, $K T 1$ ve $K T 2$ zaman noktalarında gerçekleşen ortalama değişimleri gösteren kukla değişkenlerdir. $D T 1$ ve $D T 2$ sırasıyla, $K T 1$ ve $K T 2$ zaman noktalarındaki eğimde gerçekleşen değişmeleri gösteren kukla değişkenlerdir. $K T 1$ ve $K T 2$ ise sırasıyla, birinci ve ikinci yapısal kırılma tarihlerini belirtmektedir.

$D U 1_{t}, D U 2_{t}, D T 1$ ve $D T 2$ kukla değişkenleri aşağıdaki biçimlerde tanımlanmaktadır: 


$$
\begin{aligned}
& D U 1_{t}=\left\{\begin{array}{lc}
1, & t>K T 1 \text { ise } \\
0, & \text { diğer durumlarda }
\end{array}\right. \\
& D U 2_{t}= \begin{cases}1, & t>K T 2 \text { ise } \\
0, & \text { diğer durumlarda }\end{cases} \\
& D T 1_{t}=\left\{\begin{array}{cc}
t-K T 1, & t>K T 1 \text { ise } \\
0, & \text { diğer durumlarda }
\end{array}\right. \\
& D T 2_{t}=\left\{\begin{array}{cc}
t-K T 2, & t>K T 2 \text { ise } \\
0, & \text { diğer durumlarda }
\end{array}\right.
\end{aligned}
$$

LP testinin Model CC'si için sıfır ve alternatif hipotezleri aşağıdaki gibi kurulmaktadır:

$H_{0}: \alpha=0$, Seri birim köklüdür,

$H_{1}: \alpha<0$, Seri iki yapısal kırılmayla birlikte trend durağandır.

Model CC'nin tahmin edilmesi sonucunda elde edilen $\alpha$ katsayısına ait en küçük $t$-istatistik değeri tablodaki kritik değerlerden daha küçük olması durumunda sıfır hipotezi reddedilmektedir. Bu durumda serinin iki yapısal kırılmayla birlikte trend durağan olduğu kabul edilmektedir.

\subsection{Granger Nedensellik Testi}

Granger' in (1969) geliştirdiği nedensellik testi, iki zaman serisi arasındaki nedensel ilişkiyi ve ilişkinin yönünü sınamak için tanımlanmıştır. Bu testte incelenen zaman serilerinin birim kök içermediği ve stokastik bir sürece sahip olduğu varsayılmaktadır. Granger nedensellik modellerinin çözümü için aşağıda verilen Lütkepohl'un (2005) vektör otoregresif modeli (VAR) tahmin edilmektedir:

$$
\begin{aligned}
& X_{2 t}=\beta_{1}+\sum_{i=1}^{p} \theta_{i} X_{2 t-i}+\sum_{j=1}^{r} \varphi_{i} X_{1 t-j}+\varepsilon_{1 t} \\
& X_{1 t}=\beta_{2}+\sum_{j=1}^{r} v_{i} X_{1 t-j}+\sum_{i=1}^{p} \omega_{i} X_{2 t-i}+u_{2 t}
\end{aligned}
$$

Granger nedensellik modellerinin analizinde, değişkenler arasında bir Granger nedensellik ilişkisinin olmadığını belirten sıfır hipotezi $\left(H_{0}\right)$, değişkenler arasında bir Granger nedensellik ilişkisinin olduğunu ifade eden alternatif hipoteze $\left(H_{1}\right)$ karşı sinanmaktadır. $X_{1 t}$ ve $X_{2 t}$ birer stokastik değişken olmak üzere, $X_{1 t}{ }^{\prime}$ nin $X_{2 t}{ }^{\prime}$ nin Granger nedeni olup olmadığını sınamak için Denklem (3.3) tahmin edilmektedir. $H_{0}$ ve $H_{1}$ hipotezleri ise aşağıdaki gibi oluşturulmaktadır:

$$
\begin{aligned}
& H_{0}: \varphi_{i}=0 ; t=1,2, \ldots, T \text { için } X_{1 t}, X_{2 t}{ }^{\prime} \text { nin Granger nedeni değildir, } \\
& H_{1}: \varphi_{i} \neq 0 ; t=1,2, \ldots, T \text { için } X_{1 t}, X_{2 t}{ }^{\prime} \text { nin Granger nedenidir. }
\end{aligned}
$$

Yukarıdaki hipotezlerin sınanmasında istatistiksel anlamlılık testlerinden Wald testi istatistiği kullanılabilmektedir. Hesaplanan test istatistiği belirlenen önem düzeyindeki kritik değerlerden büyükse $H_{0}$ hipotezi reddedilmektedir. Yani, $X_{1 t}{ }^{\prime}$ in $X_{2 t}{ }^{\prime}$ nin Granger nedeni olduğuna karar verilmektedir. $X_{2 t}{ }^{\prime}$ nin $X_{1 t}{ }^{\prime}$ in Granger nedeni olup olmadığını sınamak için Denklem (3.4) tahmin edilmekte olup $H_{0}: v_{i}=0$ sıfır hipotezinin istatistiksel anlamlılığı sınanmaktadır.

\section{Uygulama ve Araştırma Bulguları}

Çalışmada kullanılan değişkenlerin 2005:M1-2019:M8 dönemine ait aylık zaman serileri BDDK (2019d) ve TCMB EVDS (2019c)'den derlenmiştir. Seriler mevsimsel etkilerinden arındırılarak (Census C-13) analize dahil edilmiştir. 


\section{Tablo 2. Analizde Kullanılan Değişkenler}

\begin{tabular}{|l|l|}
\hline Sembol & Açıklama \\
\hline KARTKUL & Bireysel Kredi Kartları (milyon TL) Kullanımı Toplamı / TUFE D serisi (reeleştirilmiştir) \\
\hline SUE & Sanayi Üretim Endeksi-Toplam Sanayi (milli geliri temsilen) \\
\hline ONFA & $\begin{array}{l}\text { Bankalararası Para Piyasası Gecelik Gerçekleşen Basit Faiz Oranı Ağırlıklı Ortalama \% - } \\
\text { Düzey (para politikası faiz oranını temsilen) }\end{array}$ \\
\hline$D K$ & USD/TL Döviz Satış-Düzey (uluslararası işlemleri temsilen) \\
\hline$M 1$ & TCMB M1 Para Arzı-Düzey / TUFE D serisi (reelleştirilmiştir) \\
\hline TUFED & $\begin{array}{l}\text { Fiyat Endeksi Özel Kapsamlı (2003=100) (TUIK) TÜFE D-İşlenmemiş gıda, alkollü } \\
\text { içecekler ve tütün ürünleri hariç - (D indeksi, işlenmemiş gıdadan kaynaklanan } \\
\text { mevsimsel gelişmeler ile tütün ve alkollü içeceklerden kaynaklanan vergi düzenlemeleri } \\
\text { nedeniyle oluşan ani değişikliklerin dışlanması amacıyla tercih edilmiştir. }\end{array}$ \\
\hline
\end{tabular}

Değişkenler arasındaki nedensellik ilişkinin varlığını sınamadan önce serilerin durağanlık mertebelerini belirlemek gerekmektedir. Bu amaçla incelenen değişkenlerin birim kök araştırması için Arttırılmış Dickey-Fuller (ADF) ile LP birim kök testleri kullanılmıştır. ADF birim kök testinde, Dickey-Fuller (DF) (1979) birim kök testinin modellerine ilave gecikmeler eklenmektedir. Bu sayede zaman serilerinde ortaya çıkabilecek serisel korelasyonun önlenmesi hedeflenmektedir. ADF testinde, seride birim kökün olduğunu iddia eden $H_{0}$ sıfır hipotezi, seride birim kökün olmadığını kabul eden $H_{1}$ alternatif hipoteze karşı test edilmektedir. ADF ve LP birim kök testlerinin sonuçları Tablo 3, Tablo 4 ve Tablo 5'de verilmiştir.

Tablo 3. ADF Birim Kök Testi Sonuçları

\begin{tabular}{|c|c|c|}
\hline Değişkenler & Sabitli Model & Sabit ve Trendli Model \\
\hline \multirow[t]{2}{*}{ KARTKUL } & $-1.960093(3)$ & $-1.206257(3)$ \\
\hline & $(0.3043)$ & $(0.9056)$ \\
\hline \multirow[t]{2}{*}{$\triangle K A R T K U L$} & $-3.552262(2)$ & $-3.883012(2)$ \\
\hline & $(0.0078)^{*}$ & $(0.0148)^{* *}$ \\
\hline \multirow[t]{2}{*}{$M 1$} & $-0.429733(0)$ & $-3.094269(0)$ \\
\hline & $(0.9001)$ & $(0.1109)$ \\
\hline \multirow[t]{2}{*}{$\Delta M 1$} & $-14.21373(0)$ & $-14.17173(0)$ \\
\hline & $(0.0000)^{*}$ & $(0.0000)^{*}$ \\
\hline \multirow[t]{2}{*}{ SUE } & $-0.652022(2)$ & $-1.950731(2)$ \\
\hline & $(0.8544)$ & $(0.6235)$ \\
\hline \multirow[t]{2}{*}{$\triangle S U E$} & $-16.68935(1)$ & $-16.64148(1)$ \\
\hline & $(0.0000)^{*}$ & $(0.0000)^{*}$ \\
\hline \multirow{2}{*}{ TUFED } & $2.829365(11)$ & $2.243554(11)$ \\
\hline & $(1.0000)$ & $(1.0000)$ \\
\hline \multirow[t]{2}{*}{$\triangle T U F E D$} & $-2.608263(10)$ & $-3.596585(10)$ \\
\hline & $(0.0933)^{\star * *}$ & $(0.0331)^{* *}$ \\
\hline \multirow[t]{2}{*}{ ONFA } & $-2.470001(3)$ & $-2.434257(3)$ \\
\hline & $(0.1246)$ & $(0.3606)$ \\
\hline \multirow[t]{2}{*}{$\triangle O N F A$} & $-4.303295(2)$ & $-4.222741(2)$ \\
\hline & $(0.0006)^{*}$ & $(0.0051)^{*}$ \\
\hline \multirow[t]{2}{*}{$D K$} & $4.903354(13)$ & $2.919862(13)$ \\
\hline & $(1.0000)$ & $(1.0000)$ \\
\hline \multirow[t]{2}{*}{$\Delta D K$} & $-9.866186(1)$ & $-10.27722(1)$ \\
\hline & $(0.0000)^{*}$ & $(0.0000)^{*}$ \\
\hline
\end{tabular}

Not: * ** ve *** sırasıyla \%1, \%5 ve \%10 anlamlılık düzeyinde serilerin durağanlığını göstermektedir. Köşeli parantez içerisindeki değerler, Hannan Quinn (HQ) bilgi kriterine göre belirlenmiş uygun gecikme uzunluğu değerleridir. Parantez içerisindeki değerler ise olasılık değerlerini göstermektedir. 
Tablo 3'deki ADF birim kök testi bulgularına göre, KARTKUL,M1, SUE ,TUFED, ONFA ve DK serilerinin birinci fark değerlerinde durağan oldukları görülmüştür.

Tablo 4. LP Birim Kök Testi Model AA Sonuçları

\begin{tabular}{lcccc}
\hline Değişkenler & Test İstatistiği & $\begin{array}{c}\text { Gecikme } \\
\text { Uzunluğu }\end{array}$ & $\begin{array}{c}\text { Birinci Kırılma } \\
\text { Tarihi }\end{array}$ & $\begin{array}{c}\text { İkinci Kırlma } \\
\text { Tarihi }\end{array}$ \\
\hline KARTKUL & -4.9213 & 3 & $2011: 03$ & $2014: 01$ \\
$M 1$ & -5.0984 & 0 & $2007: 08$ & $2014: 12$ \\
$\Delta M 1$ & -14.3684 & 0 & $2007: 07$ & $2017: 03$ \\
SUE & -4.5500 & 2 & $2008: 05$ & $2010: 11$ \\
$\Delta S U E$ & -17.4374 & 1 & $2009: 02$ & $2014: 10$ \\
TUFED & -0.1245 & 11 & $2008: 09$ & $2017: 08$ \\
$\Delta$ TUFED & -7.7886 & 3 & $2008: 09$ & $2017: 07$ \\
ONFA & -4.8964 & 3 & $2008: 12$ & $2017: 08$ \\
$\Delta O N F A$ & -6.9566 & 1 & $2008: 10$ & $2010: 12$ \\
$D K$ & -5.0984 & 0 & $2007: 08$ & $2014: 12$ \\
$\Delta D K$ & -10.4633 & 1 & $2014: 08$ & $2017: 07$ \\
\hline
\end{tabular}

Not: Tablodaki gecikme uzunlukları HQ bilgi kriterine göre belirlenmiştir. \%1, \%5 ve \%10 anlamlılık düzeyindeki kritik değerler sırasıyla -6.74, -6.16 ve $-5.89^{\prime}$ dur. Kritik Değerler, Ben-David vd.'nin (2003) çalışmasından alınmıştır.

Tablo 5. LP Birim Kök Testi Model CC Sonuçları

\begin{tabular}{lcccc}
\hline Değişkenler & Test İstatistiği & $\begin{array}{c}\text { Gecikme } \\
\text { Uzunluğu }\end{array}$ & $\begin{array}{c}\text { Birinci Kırılma } \\
\text { Tarihi }\end{array}$ & $\begin{array}{c}\text { İkinci Kirılma } \\
\text { Tarihi }\end{array}$ \\
\hline KARTKUL & -7.7448 & 3 & $2009: 06$ & $2014: 01$ \\
$M 1$ & -5.204 & 0 & $2007: 08$ & $2016: 09$ \\
$\Delta M 1$ & -14.4579 & 0 & $2007: 02$ & $2017: 03$ \\
SUE & -5.6615 & 2 & $2008: 07$ & $2017: 07$ \\
$\Delta$ SUE & -17.9580 & 1 & $2008: 10$ & $2016: 07$ \\
TUFED & -4.1111 & 11 & $2012: 06$ & $2017: 05$ \\
$\Delta$ TUFED & -7.7261 & 3 & $2008: 09$ & $2017: 07$ \\
ONFA & -4.9002 & 3 & $2007: 09$ & $2010: 10$ \\
$\Delta$ ONFA & -6.9867 & 1 & $2008: 11$ & $2014: 02$ \\
$D K$ & -3.8828 & 13 & $2013: 07$ & $2017: 06$ \\
$\Delta D K$ & 10.5655 & 1 & $2014: 12$ & $2017: 07$ \\
\hline
\end{tabular}

Not: Tablodaki gecikme uzunlukları HQ bilgi kriterine göre belirlenmiștir. \%1, \%5 ve \%10 anlamlılık düzeyindeki kritik değerler sırasıyla $-7.19,-6.75$ ve -6.48 'dır. Kritik Değerler, Ben-David vd.'nin (2003) çalışmasından alınmıştır.

Tablo 4' de verilen LP birim kök testi sonuçlarına göre, KARTKUL serisinin düzey değerlerinde iki kırılmayla birlikte trend durağan olduğu saptanmıştır. $M 1, S U E$, TUFED , ONFA ve DK serilerinin ise birinci fark değerlerinde iki kırılmayla birlikte trend durağan oldukları tespit edilmiştir.

ADF ve LP birim kök testlerinin analiz sonuçları karşılaştırıldığında, KARTKUL serisi dışındaki tüm serilerde birim kök sonuçlarının paralel olduğu gözlemlenmiştir. Analizi yapılan dönemde 2008 Küresel Krizi yaşanmış, düzenleyici otoriteler kredi kartlarıyla ilgili yasal düzenlemelerde değişiklikler yapmışlardır. Dolayısıyla analize konu edilen döneme ilişkin serilerde yapısal kırılmaların olması muhtemeldir. Literatürde incelenen dönem içerisinde serilerde yapısal kırılmaların olduğu düşünülüyorsa, bu durumun biri kök sınama modelinde dikkate alınması gerektiğine işaret edilmekte; olası yapısal kırılmaların dikkate alınmaması halinde, modelin tahmin sonuçlarının yanıltıcı olabileceğine vurgu yapılmaktadır. Bahsedilen sebeple, Granger nedensellik analizinde LP birim kök testinin sonuçları dikkate alınmıștır. Yani nedensellik analizi için KARTKUL serisinin düzey değerleri ve $M 1, S U E, T U F E D, O N F A$ ve $D K$ serilerinin birinci fark değerleri kullanılmıştır. 
Çalışmada serilerin dură̆anlık mertebeleri tespit edildikten sonra seriler arasındaki nedensel ilişkilerin araştırılması için Granger nedensellik yöntemi kullanılmıştır. Analiz sonuçları Tablo 6’ da verilmiştir.

Tablo 6. Granger Nedensellik Testi Sonuçları

\begin{tabular}{|c|c|c|c|}
\hline Nedensellik Yönü & $\begin{array}{c}\text { Ki-Kare Test- } \\
\text { İstatistiği }\end{array}$ & $\begin{array}{l}\text { Gecikme } \\
\text { Uzunluğu }\end{array}$ & $\begin{array}{c}\text { Olasılık } \\
\text { Değeri }\end{array}$ \\
\hline$M 1 \rightarrow K A R T K U L$ & 16.34521 & 4 & $0.0026^{*}$ \\
\hline$K A R T K U L ~ \not ~ M 1$ & 5.295333 & 4 & 0.2583 \\
\hline$S U E \rightarrow K A R T K U L$ & 9.857197 & 4 & $0.0429 * *$ \\
\hline$K A R T K U L \not \triangle S U E$ & 3.435446 & 4 & 0.4878 \\
\hline TUFED $\rightarrow$ KARTKUL & 25.36744 & 4 & $0.0000^{*}$ \\
\hline KARTKUL $\rightarrow T U F E D$ & 3.219965 & 4 & 0.5217 \\
\hline ONFA $\rightarrow$ KARTKUL & 22.45621 & 5 & $0.0004^{*}$ \\
\hline$K A R T K U L \nrightarrow \rightarrow O N F A$ & 1.591539 & 5 & 0.9023 \\
\hline$D K \rightarrow K A R T K U L$ & 22.03469 & 4 & $0.0002^{*}$ \\
\hline$K A R T K U L \not \triangle D K$ & 3.939502 & 4 & 0.4143 \\
\hline
\end{tabular}

Not: * ve ***sırasılla \%1 ve \%5 anlamlılık düzeyinde nedenselliği göstermektedir. Tablodaki gecikme uzunlukları HQ bilgi kriterine göre belirlenmiştir.

Tablo 6' da verilen nedensellik sonuçlarına göre, $M 1$, SUE , TUFED , ONFA ve DK'den KARTKUL 'a doğru tek yönlü nedenselik ilişkisinin olduğu bulunmuştur. Buradaki bulgulara göre, Türkiye'de M1, SUE , TUFED , ONFA ve DK değişkenlerinin KARTKUL değişkeni üzerindeki istatistiksel olarak anlamlı etkilerinin olduğu görülmektedir. Öte yandan KARTKUL değişkeninin M1, SUE, TUFED , $O N F A$ ve $D K$ değişkenleri üzerinde istatistiki açıdan bir etkisinin olmadığı söylenebilir.

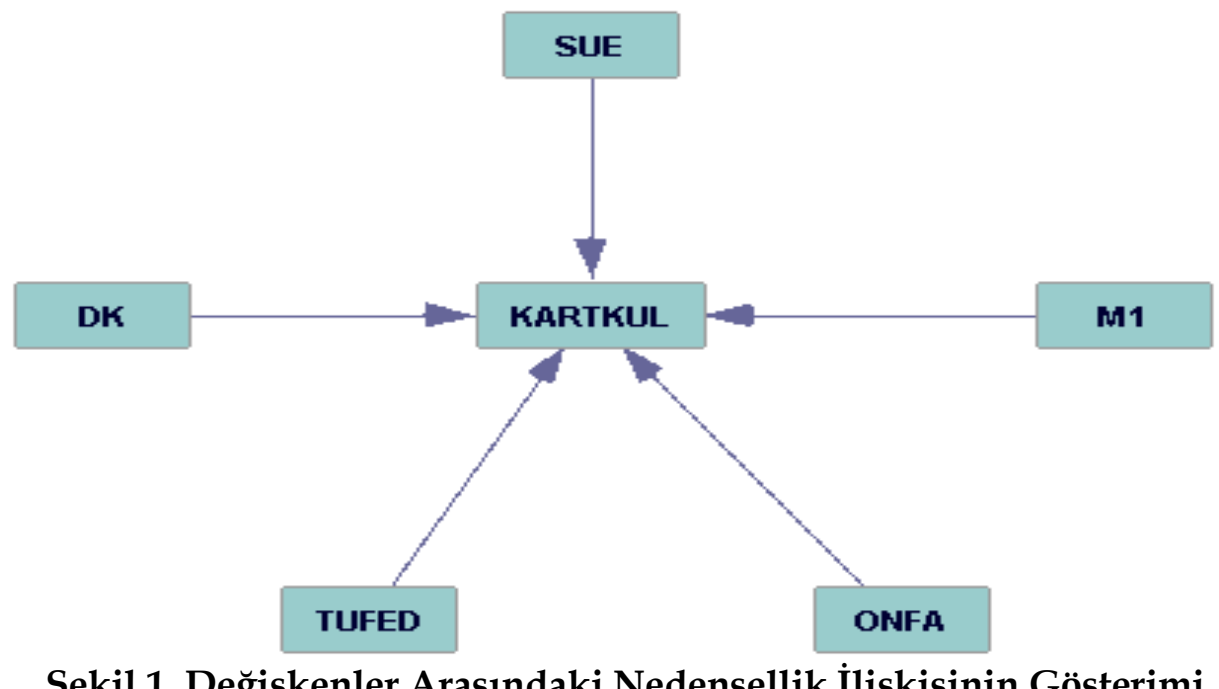

Türkiye'de $M 1, S U E, T U F E D$, ONFA ve $D K$ değişkenlerinin KARTKUL değişkeni üzerindeki etkisini belirlemeye yönelik olarak yapılan bu çalışmada, 2005:M1-2019:M8 dönemine ait aylık veriler kullanılmıştır. Etkileşimin analizi için Granger nedensellik yöntemi kullanılmıştır. Nedensellik testi bulgularında nedensellik ilişkisinin, M1, SUE , TUFED , ONFA ve DK'den KARTKUL 'a doğru tek yönlü olduğu saptanmıştır (bkz. Şekil 1).

Çalışmada elde edilen M1 para arzından kredi kartı kullanımına doğru tek yönlü nedensellik ilişkisi bulgusu Kabarlarlı (2015), Karpuz (2012), Yılmazkuday ve Yazgan (2011) tarafından yapılan çalışmaların bulgularını desteklemektedir. Milli geliri temsilen kullanılan sanayi üretim endeksinden kredi kartı kullanımına doğru tek yönlü nedensellik ilişkisi sonucu Prabheesh ve 
Rahman (2019), Mazibaş ve Tuna (2017) , Kabarlarlı (2015), Uzgören vd. (2007), Yılmazkuday (2010) tarafından bulunan sonuçlarla paralellik göstermektedir. Çalışmada elde edilen tüketici fiyat endeksinden kredi kartı kullanımına doğru tek yönlü nedensellik sonucu Kabarlarlı (2015), Uzgören vd. (2007) tarafından elde edilen bulguları desteklemektedir. Faiz oranlarından kredi kartı kullanımına doğru tek yönlü nedensellik ilişkisi sonucu Mazibaş ve Tuna (2017), Yüksel vd. (2016), Kabarlarlı (2015) tarafından bulunan sonuçları desteklemektedir. Çalışmada döviz kurlarından kredi kartı kullanımına doğru tek yönlü nedensellik ilişkisi sonucu Balaylar vd. (2017) tarafından elde edilen bulgularla paralellik göstermektedir.

\section{Sonuç ve Değerlendirme}

Çalışmadaki temel amacımız kredi kartı kullanım hacmini etkileyen faktörlerin anlaşılmasına katkı sağlamaktır. Bu amaç doğrultusunda öncelikle değişkenlere ilişkin durağanlık seviyelerinin tespiti amacıyla ADF ile LP birim kök testleri uygulanmıştır. Analizde kullanılan değişkenler 2008 küresel krizi öncesi, kriz dönemi ve kriz sonrasında yaşanan şoklar karşısında yapısal kırılmaya uğramışlardır. ADF birim kök testi ile iki yapısal kırılmayı dikkate alan LP birim kök testinin sonuçlarına göre bireysel kredi kartı kullanım hacmi seviyede durağanlaşırken, diğer değişkenlerin birinci fark seviyelerinde durağanlaştıkları tespit edilmiştir. Değişkenler arasındaki etkileşimin tespiti için kullanılan Granger nedensellik analizi sonuçlarına göre, kısa dönemde milli gelir, fiyatlar genel düzeyi, politika faiz oranı, döviz kuru ve merkez bankası dar para arzından ( $M 1)$ kredi kartı kullanımına doğru tek yönlü nedensellik ilişkisi bulunmaktadır.

Tüketici kredi kartları borçlanma, tüketim ve tasarruf kararları doğrultusunda kullanılmaktadır. Diğer bir deyişle tüketiciler likidite ve tedbir amacı ile kısa ve uzun vadeli borçlarını döndürmek (yaşam döngüsü) amacıyla harcama yapmaktadır. Özellikle kriz dönemleri ve ertesinde düşük gelir grubunun kredi kartı borçluluğunun arttığ1 görülmektedir. Bu durum ucuz finansman sağlayamayan kesimin yüksek maliyetle borçlanarak gelir dağılımının daha da bozulmasına zemin hazırlayabilir. Tüketici harcamalarının bir kısmı kredi kartlarıyla yapılarak nakit çıkışıın ertelenmesi sağlanmaktadır. Kredi kartı kullanımı nakit kullanımının ikamesidir. Para arzındaki değişiklikten kredi kartı kullanımının etkilenmesi beklenmektedir.

Özetle, analiz sonuçlarına göre makroekonomik göstergeler ile para arzı $(M 1)$ bireysel kredi kartı kullanımının tek yönlü nedeni olduğu bulgusu düzenleyici ve denetleyici kurumların kredi kartı temerrüt riskini takip etmesinin önemli olduğunu göstermektedir.

Kredi kartı kullanımındaki artış paranın dolaşım hızını arttırmaktadır. Parasal otoritelerce piyasaya müdahale edilmemesi halinde paranın dolaşım hızındaki artış enflasyona neden olabilmektedir. Türkiye' de toplam tüketici kredileri içinde takibe dönüşüm oranı en yüksek kredi türü bireysel kredi kartlarıdır. Özellikle kriz dönemlerinde kredi seçeneklerinin kısıtlı olması bazı tüketicilerin kredi kartlarını kullanarak fazla borçlanmaları sonucu borçlarının tamamını ödeyememelerine dolayısıyla temerrüde düşmelerine neden olabilmektedir. Politika yapıcıların ve denetleyici kurumların kredi kartı borçluluğunu teşvik eden yüksek limit tahsisi, uzun vadeli taksitlendirme, ve ödül puan uygulamalarını kontrol altında tutması önemlidir. Özellikle kredi kartı temerrüt riskininin takip edilmesi önerilmektedir. Bununla birlikte kredi kartının yaygın kullanımı ticaretin verimliliğine katkı sağlamaktadır. Dolayısıyla düşük gelir grubu ve kredi kısıtı olan tüketicilerin gözetildiği ucuz kredi seçeneklerinin oluşturulması da gelir dağılımı adaletinin tesis edilmesine katkı sağlayabilir.

\section{Kaynakça}

Acar Balaylar, N.; Yalçın Kayacan, E. \& Emeç, H. (2017). 2008 Küresel Krizi Bağlamında Döviz Kurları ve Türkiye' de Dövize Endeksli Banka Kredileri Arasındaki Eştümleşme ve Nedensellik İlişkisi, Yönetim ve Ekonomi, Manisa Celal Bayar Üniversitesi İ.I.B.F., Y11:2017, Cilt:24, Say1:3, 687704.

Akın, G.G.; Aysan, A.F.; Dasdogen, S.\& Yildıran, L. (2019). Credit Card Debt: Nescience or Necessity?, Economic Research Forum 2019, Working Paper No.1315, July 2019. 
BDDK (2019a). Bankacılık Düzenleme ve Denetleme Kurumu. Türk Bankacılık Sektörü Temel Göstergeleri Eylül 2019, https://www.bddk.org.tr/ContentBddk/dokuman/duyuru_0744_ 01.pdf>, (Erişim Tarihi: 21.11.2019).

BDDK (2019b). Bankacılık Düzenleme ve Denetleme Kurumu. Banka Kartları ve Kredi Kartları Kanununa İlişkin Düzenlemeler, <https://www.bddk.org.tr/Content Bddk/dokuman/ mevzuat_0926.pdf>, (Erişim Tarihi: 21.11.2019).

BDDK (2019c). Bankacılık Düzenleme ve Denetleme Kurumu. Türk Bankacılık Sektörü Temel Göstergeleri Haziran 2019, <https://www.bddk.org.tr/ContentBddk/dokuman/duyuru_ 0689_01.pdf>, (Erişim Tarihi: 21.11.2019).

BDDK (2019d). Bankacilık Düzenleme ve Denetleme Kurumu, <https://www.bddk.org.tr/ BultenAylik/tr/Home/Gelismis>, (Erişim Tarihi: 22.11.2019).

Ben-David, D.; Lumsdaine, R.\& Papell, D.H. (2003). Unit Root, Postwar Slowdowns and Long-Run Growth: Evidence From Two Structural Breaks, Empirical Economics, 28(2), 303-319.

BKM (2019a). Bankalararası Kart Merkezi, Dönemsel Bilgiler, <https://bkm.com.tr/yerli-kredikartlarinin-yurt-ici-ve-yurtdisi-kullanimi>, (Erişim Tarihi: 20.11.2019).

BKM (2019b). Bankalararası Kart Merkezi İnternet Sayfası, Kartlı Ödeme Sistemlerinin Ekonomiye Katkıları, <https://bkm.com.tr/faydali-bilgiler/kart-bilinci/kartli-odeme-sistemlerinineko nomiye -katkilari/>, (Erişim Tarihi: 28.11.2019).

Dickey, D. A.,; Fuller, W. A. (1979). Distribution of the Estimators for Autoregressi-ve Time Series With a Unit Root, Journal of the American Statistical Association, 74(366), 427-431.

Eroğlu E. (2018). TCMB Merkezin Güncesi Bloğu, Finansal Piyasalar 27/06/2018, Hanehalk1 Borçluluk Seviyesine Karşılaştırmalı Bir Bakış, <http://tcmbblog.org/wps/wcm /connect/blog/tr/main\%20menu/analizler/hanehalki-borcluluk-seviyesine-karsilastirmalibir-bakis>, (Erişim Tarihi: 28.11.2019).

Freedman, C. (2000). Monetary Policy Implementation: Past Present and Future-Will The Advent of Electronic Money Lead to the Demise of Central Banking?, International Finance, 3, 211-227.

Friedman, B.M. (1999). The Future of Monetary Policy: The Central Bank as an Army with only a Signal Corps?, International Finance, 2, 321-338.

Fulford, S.L.; Schuh, S. (2017). Credit Card Utilization and Consumption Over The Life Cycle and Business Cycle, Federal Reserve Bank of Boston, Working Papers September 2017, 17-14, 1-50.

Geanakoplos, J.; Dubey, P. (2010), Credit Cards and Inflation, Games and Economic Behavior, 70, 325353.

Granger, C.W.J. (1969). Investigating Causal Relations by Econometric Models and Cross-Spectral Methods, Econometrica, 37(3), 424-438.

Granger, C.W.J. (1980). Testing for Causlity: a Personal Viewpoint, Journal of Economic Dynamics and Control, (2), 329-352.

Kabarlarlı, E. (2015). Türkiye"de Kredi Kartı Kullanımınını Para Politikasındaki Rolü ve Etkileri, Sosyoekonomi 2015, 23(26), 119-138.

Karpuz, E. (2012). Ödeme Sistemleri ve Araçlarının Artan Kullanımı: Kredi Kartı Kullanımının Para Politikası Etkinliğine Etkisi, TCMB Bankacılık ve Finansal Kuruluşlar Genel Müdürlüğü, Uzmanlık Yeterlilik Tezi, Nisan 2012.

Lumsdaine, R.L.; Papell, D.H. (1997). Multiple Trend Breaks and The Unit Root Hypothesis, The Review of Economics and Statistics, 79(2), 212-218.

Lütkepohl, H. (2005). New Introduction to Multiple Time Series Analysis, Springer-Verlag, Berlin Heidelberg, Germany.

Mazibaş, M. ; Tuna, Y. (2017). Understanding the Recent Growth in Consumer Loans and Credit Cards in Emerging Markets: Evidence from Turkey, Emerging Markets Finance and Trade, 53:10, 2333-2346.

Perron, P. (1989). The Great Crash, the Oil Price Shock, and the Unit Root Hypothesis, Econometrica, 57(6), 1361-1401. 
Phillips, P.C.B. ; Perron, P. (1988). Testing for a unit root in time series regression. Biometrika, 75, 33546.

Prabheesh, K.P.; Rahman, R.E. (2019). Monetary Policy Transmission and Credit Cards: Evidence From Indonesia, Bulletin of Monetary Economics and Banking, 22(2), 137-162.

Sevüktekin, M.; Nargeleçekenler, M. (2010). Ekonometrik Zaman Serileri Analizi: Eviews Uygulamalı (3. Baskı), Nobel Yayın Dağıtım, Ankara.

Sönmezler, G.; Gündüz, İ.O. \& Torun, M. (2019). Türkiye' de Kredi Kartı Harcamaları ile Tüketici Güven Endeksi ve Enflasyon Arasındaki İlişki Üzerine Ampirik Bir Çalışma, Ç.Ü. Sosyal Bilimler Enstitüsü Dergisi, 28(1), 17-29.

Stavins, J. (2018). Credit Card Debt and Consumer Payment Choce:What Can We Learn from Credit Bureau Data?, Federal Reserve Bank of Boston Working Papers, No.18-7, October 2018, 1-35.

TCMB EVDS (2019a). Türkiye Cumhuriyet Merkez Bankası Elektronik Veri Dağıtım Sistemi, Kredi Kartı Harcamalarının Sektörel Dağılımı, <https://evds2. tcmb.gov.tr/index.php? /evds/dashboard/4871>, (Erişim Tarihi: 29.11.2019).

TCMB EVDS (2019b). Türkiye Cumhuriyet Merkez Bankası Elektronik Veri Dağıtım Sistemi, Toplam Kredi-Hanehalk1 (GSYİH Yüzdesi), <https://evds2.tcmb.gov. tr/index.php? /evds/dashboard/4770>, (Erişim Tarihi: 29.11.2019).

TCMB EVDS (2019c). Türkiye Cumhuriyet Merkez Bankası Elektronik Veri Dağıtım Sistemi, <www.tcmb.evds.gov.tr>, (Erişim Tarihi: 24.11.2019).

Uzgören, N.; Ceylan, G. \& Uzgören, E. (2007). Türkiye'de Kredi Kartı Kullanımını Etkileyen Faktörleri Belirlemeye Yönelik Bir Model Çalışması, Yönetim ve Ekonomi, Celal Bayar Üniversitesi İ.İ.B.F., 2007, 14(7), 247-256.

WorldBank (2018). Global Findex Database, 2018 The Little Data Book on Financial Inclusion, 150. Yazgan, M. E. ; Y1lmazkuday, H. (2011). Effects of Credit and Debit Cards on The Currency Demand, Applied Economics, 41, 2115-2123.

Yilmazkuday, H. (2010), Monetary Policy and Credit Cards: Evidence from a Small Open Economy, DETU Working Paper 10-10, September 2010, 1-19.

Yüksel, S.; Zengin, S.\&Kartal, M.T. (2016). Identifying the Macroeconomic Factors Influencing Credit Card Usage in Turkey by Using MARS Method, China-USA Business Review, Dec. 2016, Vol. 15, No. 12, 611-615.

Zivot, E.; Andrews, D. (1992). Further Evidence on the Great Crash, the Oil-Price Shock and the UnitRoot Hypothesis, Journal of Business Economic Statistics, 10(3), 251-270.

\section{Aim and Scope}

\section{Extended Abstract}

With the spread of individual credit card usage, it is possible to examine the recorded consumption, borrowing and saving behaviors of households and the reflections of the individual's economic behaviors to the economy. In this study, the relationship between individual credit card usage with money supply and economic indicators were investigated in Turkey.

\section{Methods}

The data set of the real volume of individual credit card transaction (KARTKUL) and the Central Bank Of The Republic of Turkey(CBRT)'s real money supply(which is defined as money supply in Turkish Liras over TUFED) M1, industrial production index(SUE), consumer price index-D (TUFED ) and interbank overnight interest rate (ONFA) and USD exchange rate ( $D K$ ) were used, for the monthly period over 2005M1-2019M8. Granger causality method was used to determine the interaction between variables.

\section{Findings}

Granger causality analysis results show that the unidirectional causality relationship from industrial production index, consumer price index, interest rate, money supply and exchange rate to credit 
cards usage. According to the findings here, M1, SUE, TUFED , ONFA and DK variables have found to be a statistically significant effect on the KARTKUL variable. On the other hand, the KARTKUL variable does not affect the other variables. In summary, analysis results indicate that individual credit card usage is affected by economic indicators and money supply when consumer use credit card.

\section{Conclusion}

The consumer uses credit cards in line with borrowing, consumption and savings decisions. Consumers make their expenditures for liquidity and precautionary measures. Also, individuals spend money to convert their short and long term debts. It is observed that the credit card indebtedness of the low-income group increased especially during and after the crises. This situation may cause borrowers who do not find cheap financing to borrow at high costs and disrupt the income distribution. Another reason for using credit cards is to make some of the consumer expenditures with credit cards and to postpone the cash outflow. In summary, the widespread use of credit cards contributes to the efficiency of trade. However, it also increases the circulation rate of money and may cause inflation if monetary authorities do not intervene the market. Particularly in the crisis period, limited credit may cause some consumers to borrow extra by using their credit cards, failing to repay all their debts and default. It is useful for policymakers and supervisory agencies to allocate high limits that encourage credit card indebtedness, to make long-term installments, and to control reward points. Additionally, the creation of cheap credit options for lowincome consumers with credit constraints may contribute to achieving a fair distribution of income. 